\title{
DECISIONES TRADUCTORAS Y EFECTOS EN LA LECTURA: ESTUDIO DE DOS TRADUCCIONES AL ESPAÑOL DE "DEVANEIO E EMBRIAGUEZ DUMA RAPARIGA" DE CLARICE LISPECTOR ${ }^{1}$
}

Andrés Ramos García 1

${ }^{1}$ El Colegio del México, Cidade do México, México

\begin{abstract}
Resumen: El siguiente artículo presenta una crítica de dos traducciones al español de "Devaneio e embriaguez duma rapariga", cuento de la escritora brasileña Clarice Lispector que tiene la peculiaridad de haber sido escrito con características de la variante europea del portugués. Para el análisis me baso en las categorías propuestas por Lance Hewson en $A n$ Approach to Translation Criticism que ayudan a describir elecciones (gramaticales, lexicales, etc.) de los traductores y sus potenciales efectos en la lectura e interpretación de un texto literario. Con esta base, se puede exponer la estrategia traductora de Cristina Peri Rossi y de la dupla Edgardo Russo y Mario Cámara.
\end{abstract}

Palabras clave: Crítica de Traducciones; Clarice Lispector; Lance Hewson; Decisiones Traductoras; Efectos en la Lectura

\section{TRANSLATIONAL CHOICES AND EFFECTS ON READING: A STUDY ON TWO TRANSLATIONS INTO SPANISH OF' 'DEVANEIO E EMBRIAGUEZ DUMA RAPARIGA' BY CLARICE LISPECTOR}

Abstract: The following paper presents a critique of two translations into Spanish of "Devaneio e embriaguez duma rapariga", a short story by the

\footnotetext{
${ }^{1}$ Agradezco a la Dra. Leandra Cristina de Oliveira del Departamento de Língua e Literatura Estrangeiras de la UFSC por proporcionarme un par de referencias bibliográficas, así como al Lic. Víctor Ruiz Chávez por algunas pertinentes observaciones sobre el portugués europeo.
} 
Brazilian writer Clarice Lispector that has the peculiarity of being written with characteristics of European Portuguese. The study method is based on Lance Hewson's categories in An Approach to Translation Criticism that describe translational choices, and their potential effects on reading and interpretation of a literary text. By doing so, Cristina Peri Rossi's, and Edgardo Russo's and Mario Cámara's collaborative translation strategies become clearer and some general considerations about their work can be typified.

Keywords: Translation Criticism; Clarice Lispector; Lance Hewson; Translational Choices; Effects on Reading

Una de las figuras más importantes del ámbito literario brasileño, por su innovación, su impacto en las letras latinoamericanas y su relevancia mundial es Clarice Lispector. No puede pensarse en este prestigio internacional sin el papel desempeñado por la traducción. Stefan Helgesson explica así el éxito de Lispector:

las capacidades a nivel trasnacional del inglés y el portugués eran y siguen siendo sumamente desiguales, a pesar del hecho de que ambas son lenguas 'globales' [...]. No sorprende pues que el éxito internacional de Lispector sea póstumo y fuera motivado en particular por la promoción de su trabajo que hizo Hélène Cixous en París (Helgesson 319). ${ }^{2}$

En este trabajo presento una crítica de dos traducciones al español, una de Cristina Peri Rossi y la otra de Mario Cámara y Edgardo Russo, de "Devaneio e embriaguez duma rapariga", cuento que

\footnotetext{
${ }^{2}$ En inglés en el original. De aquí en adelante indicaré en nota al pie las citas originales en inglés, todas las traducciones son mías: "the transnationally enabling capacities of English and Portuguese were and remain highly uneven, despite the fact that both are 'global' languages [...]. It comes as no surprise that Lispector's international success is posthumous and was triggered in particular by Hélène Cixous's Parisian promotion of her work".
} 
abre el libro Laços de Família, basada en las categorías propuestas por Lance Hewson en An Approach to Translation Criticism.

\section{Clarice y su obra}

Lispector nació en Ucrania en 1920, sin embargo, llegó a Brasil apenas a los dos meses de edad. Publicó su primera novela, con tan sólo veintitrés años, Perto do Coração Selvagem (1944) a la que le siguió más de una veintena de libros entre novelas, ensayos, cuentos y hasta libros infantiles, "[c]asi toda su obra se afinca en los ambientes y en las ciudades brasileñas, particularmente en Río de Janeiro, aunque vivió mucho tiempo en el extranjero" (Cosío Woodward 17). Su muerte ocurrió en 1977, víctima de un cáncer inoperable.

Se ha dicho mucho acerca de la obra de Clarice Lispector, con un consenso sobre la complejidad de sus textos por el uso del lenguaje, la técnica narrativa y la reflexión sobre la palabra y la función del lenguaje. Uno de sus temas recurrentes es la introspección de los personajes y su conciencia despierta ante un hecho cotidiano. Alfredo Bosi, además de identificar las renovaciones literarias de Lispector, propone tres características esenciales de la narrativa de la brasileña: el uso de la metáfora insólita, el flujo de la conciencia y la ruptura con el argumento (Bosi 424).

Por la naturaleza de este trabajo, lo que más me interesa es el uso de la lengua de Lispector. En "Devaneio e embriaguez duma rapariga", la autora se sirve del lenguaje para caracterizar a su personaje e involucrar a la voz narrativa en la diégesis, una de las características esenciales del cuento, juicio que puede extenderse a toda su obra, pues ésta "se asienta en una investigación del lenguaje, de las relaciones humanas y, sobre todo, en un análisis minucioso del alma femenina", así "la lengua es el elemento central de su obra" (Losada 9-10).

En la cita anterior se vislumbra otro de los aspectos discutidos alrededor de Lispector y sus personajes: la condición de la mujer. De dicha discusión, rescato el trabajo de Saldías Palomino que re- 
piensa lo que se ha dicho sobre "la escritura femenina" como una manera de inferiorizar la literatura de mujeres (Saldías Palomino 73); la autora concluye que "el discurso introspectivo de la narrativa de Clarice Lispector conduce a sus lectores/as a cuestionar los márgenes fijados por la lectura canónica masculina para la producción literaria de mujeres, mediante el uso transgresor del lenguaje para enunciar esa 'observación interior' o introspección” (Saldías Palomino 82). Esto es relevante pues Clarice tiene prototípicamente a mujeres por protagonistas y este cuento no es una excepción. No pretendo, sin embargo, realizar un comentario literario, sino uno enfocado en sus traducciones al español.

Recupero entonces la cuestión del lenguaje que

no es solamente un instrumento de la trama, sino que es el protagonista en los textos [de Lispector]. En Clarice, como en todo gran escritor, la complementariedad entre forma y contenido se confunde, lo que dificulta el trabajo del traductor quien tiende, en general, a lidiar con la prosa y la traducción semántica (Ferreira de Freitas 247). ${ }^{3}$

Se configura aquí ya una de las dificultades generales de la traducción literaria, además, en este cuento hay un elemento que considero intraducible, como se verá más adelante.

El libro, su segunda reunión de cuentos, del que se desprende el texto que analizo, Laços de Família (en adelante, LdF), se publicó en 1960 y ha merecido numerosos elogios y diversos trabajos académicos. Corrêa dos Santos en su presentación afirma que Clarice "[c]om esse conjunto de contos elevou a narrativa literária curta, bem como toda arte da escritura imaginativa, a uma dimensão que só raras vezes foi atingida no Brasil” (Corrêa dos Santos 5).

3 "is no mere instrument for a plot: it is a protagonist in [Lispector's] writings. In Clarice, as in great writers, the complementarity between form and content is entangled, which hinders the work of the translator who tends, generally, to deal with prose and semantic translation". 
Compara los cuentos con cuadros plásticos, como piezas musicales (Corrêa dos Santos 10,13) y, por supuesto, menciona la presencia de mujeres: "Nunca antes o universo feminino foi tão minuciosamente palmilhado" (Corrêa dos Santos 11). El buen recibimiento de este volumen puede reflejarse en sus traducciones: al sueco, al neerlandés, al inglés, al francés, al italiano y al español.

\section{Perfiles de los traductores al español}

En español, LdF se ha traducido tres veces, la primera por Haydée M. Jofre Barroso para Editorial Sudamericana en 1973, la cual me fue imposible consultar; la editorial barcelonesa Montesinos pone en circulación en 1988 la traducción de Cristina Peri Rossi; y, recientemente, en 2010, Edgardo Russo y Mario Cámara publicaron la suya en Buenos Aires bajo el sello El cuenco de plata.

Cristina Peri Rossi (1942) es una renombrada escritora y activista uruguaya; en 1972 se exilió a causa de la dictadura que vivía su país. Ha residido mayoritariamente en Barcelona. De Lispector tradujo, además de LdF, el volumen Onde Estivestes de Noite (1979), publicado como Silencio (1995), el título de uno de los cuentos, por Grijalbo. Peri Rossi, admiradora de la escritora brasileña, la considera "responsable de la modernización de la literatura de su país al introducir 'la ruptura del yo, la introspección, la sensación como forma de identidad, la duda allí donde el cuento omnisciente proponía la certeza" (Saldías Palomino 71). La uruguaya ha dicho sobre la traducción:

el traductor penetra (soy consciente de la acepción sexual del término) el texto como quien conquista un territorio, lo exprime, lo explota, lo desmenuza para poseerlo. También es verdad que se enfrentará a un escollo inevitable: aunque haya leído el libro que el autor escribió, se enfrentará a una frustración: no hay traducción, sólo hay versión. Una palabra en una lengua nunca sonará igual en otra, con lo cual se pierde una 
parte invalorable del texto, que es su sonoridad. [...] Nadie conoce mejor un texto que quien lo traduce (Peri Rossi, $\mathrm{s} / \mathrm{p}$ ).

Edgardo Russo (1949-2015) fue un poeta, editor, ensayista y traductor argentino. Publicó obras de varios escritores latinoamericanos, como Marosa di Giorgio, Manuel Puig, Felisberto Hernández, Rodolfo Walsh y Rubem Fonseca, y también de nombres reconocidos de otras latitudes como Duras, Artaud y Gombrowicz; tradujo obras de Bloom, Steiner, James. En 2003 formó parte del equipo fundador de El cuenco de plata, sello que se ha consolidado en Argentina como una de las editoriales independientes más reconocidas y con un sólido catálogo. Russo consideraba su labor de editor como lo más importante: "Mi actividad como editor es casi más gratificante que la de publicar un libro propio. Es la literatura más allá del escritor, es poner al alcance de los lectores autores u obras olvidadas" (Erlan, s/p).

Mario Cámara es académico de la Universidad de Buenos Aires en donde imparte la cátedra de literatura brasileña. Además de LdF, en colaboración con Russo, para El cuenco de plata, tradujo también la emblemática novela de Lispector, La pasión según G. H. Sobre traducir a Lispector, Cámara opina que dentro de lo más desafiante está encontrar el tono de la brasileña: "La literatura de Clarice es muy traicionera por su aparente sencillez [...]. El desafío fue poder traducir no sólo sus palabras, sino sus climas"; asimismo sobre su labor como traductor, expresa: "traducir refuerza el rol de lector que uno tiene. Es una tarea microscópica que ayuda a mejorar la lectura del texto" (Selicki Acevedo, s/p).

\section{Metodología}

Defino ahora la metodología que seguiré para realizar el ejercicio crítico de las traducciones. Parto de An Approach to Translation Criticism de Lance Hewson. No pretendo seguir todo su método, específicamente el análisis cuantitativo, ni llevarlo al ma- 
cronivel; el investigador tiene como uno de sus objetivos examinar decisiones de traducción en pasajes seleccionados para plantear efectos potenciales en la interpretación. Me serviré entonces de las categorías que define en el análisis en un micronivel, como la elección de la sintaxis, del léxico, gramaticales, etc. (Hewson 58-83) y también de los efectos descritos bajo el nombre de mesonivel.

Como efectos de voz, Hewson define tres: un aumento ( $a c$ cretion), que sucede cuando el traductor opta por decisiones que aportan algo adicional a las voces del original (Hewson 85); una reducción (reduction), es decir, una percepción general de que hay menos elocuencia o impacto en las características de estilo que se eligieron; y una deformación (deformation), que se presenta cuando hay cambios en la focalización o en las decisiones del autor concernientes al discurso, directo, indirecto o indirecto libre (Hewson 86). Respecto a los efectos interpretativos, a partir de las decisiones traductoras, Hewson establece tres también: la contracción (contraction), que reduce las vías potenciales de interpretación; la expansión (expansion) que abre más vías heurísticas; y la transformación (transformation) que supone una modificación que no revela la relación entre las lecturas potenciales del texto fuente en relación con el texto meta (Hewson 86-88).

Estas categorías serán útiles para describir las traducciones y partir de ellas al llevar a cabo el análisis de las decisiones traductoras. "Devaneio e embriaguez duma rapariga" se trata de una mujer casada, con hijos, que no tiene ganas de cumplir con sus obligaciones (impuestas por la sociedad en su rol de madre y esposa); en una salida a un restaurante se emborracha y al siguiente día recuerda los sucesos y, a regañadientes, piensa en que tiene que recuperar la cotidianidad. El relato cumple con la organización en cuatro movimientos que ha observado Romano de Sant'Anna en los cuentos de Lispector:

situación inicial del personaje, preparación de un incidente bajo la forma de presagio, ocurrencia del incidente y, por último, el desenlace, en el que el personaje o retorna a la 
situación inicial o permanece en la perturbación provocada por el incidente. (Pozenato 162)

Ésta también ha sido descrita de manera parecida por Cossío Woodward:

\begin{abstract}
Primero, hay una estampa casi objetiva de la situación del personaje [...]. Después, la indagación en la conciencia de sí [...]. Enseguida, el afán de comunicarse con los otros y la abrupta constatación de su imposibilidad. Luego, la revelación instantánea, la epifanía fulminante, a partir de lo cual se puede, finalmente, regresar a la normalidad (Cossío Woodward 24-25).
\end{abstract}

Esto quiere decir que estamos ante un cuento paradigmático de la autora respecto a su estructura, pero peculiar en su estilo narrativo.

\title{
4. Análisis de las traducciones
}

Desde el título, Lispector utiliza marcas distintivas del portugués europeo: la contracción duma y la palabra rapariga, poco usada en Brasil. Este rasgo se extiende a toda la narración que está construida en buena medida con discurso indirecto libre, lo que funciona para caracterizar, no explícitamente, a su protagonista: una mujer joven portuguesa, residente en Brasil, que "transgride o padrão que foi imposto à mulher pela sociedade patriarcal" (Mol; Ribeiro 183). Su devaneo "seria uma fuga da realidade, de fantasiar e de certa forma questionar a submissão imposta a ela" (ibid. 186).

La construcción de ese devaneo es fundamental en la caracterización del personaje y el cruce de voces narrativas. El uso del portugués europeo no es un mero recurso decorativo, sino uno que ayuda en la conformación de las voces narrativas; al respecto Ernani Terra afirma: 
No conto, podem-se observar, tanto por parte do enunciador quanto da rapariga, expressão de sentimentos súbitos por meio de interjeições (ai), comprobando a hipótese de um deslizamento do narrador heterodiegético para o nível do enunciado, [...]. O logos, discurso do narrador, se deixa contaminar pelo pathos da personagem (Terra, s/p).

Lispector, respecto al cuento, afirmaba: "eu falava à moda portuguesa, fazendo, ao que me parece, experiência de linguagem" (cit. por Terra, s/p), esa experiencia del lenguaje se refleja en el cuento y "consiste em se valer de recursos lexicais, morfológicos, sintáticos e fonológicos que caracterizam a variedade europeia do português" (Terra, s/p). En su trabajo, Ernani Terra hace una lista de esos recursos, entre ellos: los lexicales, rapariga, miúdos, palestrar, etc.; los morfológicos, el diminutivo en frescurazita, vestidito, fidalguita (en Brasil es más común el infijo -inh-); los sintácticos, la construcción del presente progresivo con estar a + infinitivo o la posición de los clíticos: ficou-se à cama, veio procurar-me cá à casa (más común en el portugués brasileño como proclisis: "se ficou", "me procurar").

Las diferencias entre las variedades brasileña y europea del portugués son así bastante distintivas, lo que en la traducción se presenta como irresoluble. Comienzo con el análisis. En cada unidad aparecen las páginas de donde se cita; el cuento de Lispector es de 1960 y las traducciones de Peri Rossi y de Cámara y Russo son de 1988 y 2010, respectivamente.

\section{Unidad 1}

\begin{tabular}{|c|c|c|}
\hline Lispector (17-18) & Peri Rossi (10) & Cámara y Russo (7-8) \\
\hline $\begin{array}{l}\text { Ai que quarto suculento! ela } \\
\text { se abanava no Brasil. } 0 \text { sol } \\
\text { preso pelas persianas tremia na } \\
\text { parede como uma guitarra. }\end{array}$ & $\begin{array}{l}\text { Ay, qué cuarto agradable, } \\
\text { ella se abanicaba en el } \\
\text { Brasil. El sol, preso de las } \\
\text { persianas, temblaba en la } \\
\text { pared como una guitarra. }\end{array}$ & $\begin{array}{l}\text { ¡Ay, qué cuarto confortable!, } \\
\text { ella se abanicaba en Brasil. } \\
\text { El sol aprisionado entre las } \\
\text { persianas vibraba en la pared } \\
\text { como una guitarra. }\end{array}$ \\
\hline
\end{tabular}


La oración que abre el fragmento utiliza el adjetivo en portugués suculento; la elección léxica de Peri Rossi y de Cámara y Russo difiere, pero ambos incurren en una deformación ya que el adjetivo originalmente tiene una carga semántica relacionada con el gusto, y, por tanto, sensorial; la elección de "agradable" y "confortable" pierde esa característica, por lo que a nivel interpretativo ocurre una contracción. El campo semántico es importante, pues a lo largo del cuento hay alusiones al cuerpo y a lo sensorial, que se vuelve en ciertos momentos sensualidad. En el caso de preso, Peri Rossi mantiene la palabra transparente del español, en cambio, los argentinos se deciden por "aprisionado" que añade de manera más explícita el hecho de estar en un lugar físico, una prisión, a pesar de que en portugués existe la palabra aprisionado; además, el uso de la contracción pelas da el significado del sol atrapado por las persianas, lo cual se mantiene en la primera traducción, sin embargo en la segunda se pierde con el uso de la preposición "entre", y así el sol parece haber sido apresado por algo más. Por último, en el caso del verbo tremia, la uruguaya lo deja como "temblaba" mientras que Russo y Cámara incurren en otra deformación al traducir "vibraba".

En esta primera unidad, ya se puede observar algo que se comprobará a lo largo de los siguientes fragmentos: Peri Rossi trata de apegarse más al texto original, sobre todo en elecciones de léxico, a veces hasta palabras que se escriben igual en español y portugués, como el caso de preso. En los siguientes ejemplos, además de las elecciones de léxico, observaré algunas elecciones gramaticales y de sintaxis.

\section{Unidad 2}

\begin{tabular}{|l|l|l|}
\hline Lispector (19) & Peri Rossi (11) & Cámara y Russo (9) \\
\hline Obstinada, ela não saberia & Obstinada, ella no sabría & Obstinada, ella no sabía \\
responder, estava tão rasa e & responder, estaba tan tonta & qué responder, estaba tan \\
princesa que não tinha sequer & y principesca que no había & despectiva y tan princesa que \\
onde se lhe buscar uma & siquiera dónde buscarle una & no sabía qué responder. Se \\
resposta. Zangou-se: & respuesta. & enojó: \\
\hline
\end{tabular}

Cad. Trad., Florianópolis, v. 40, ${ }^{0}{ }^{1}$, p. 168-187, jan-abr, 2020. 


\begin{tabular}{|l|l|l}
\hline — Ai que não me maces! Não & —iCuidado con & —iNo molestes! ¡No me \\
me venhas a rondar como um & molestarme! ¡No vengas & vengas a rondar como un \\
galo velho! & a rondarme como un gato & gallo viejo! \\
Ele pareceu pensar melhor e & viejo! & Él pareció pensarlo mejor y \\
declarou: & Él pareció pensarlo mejor & dijo: \\
— Ó rapariga, estás doente. & y aclaró: & -Muchachita, estás \\
& -Muchacha, estás & enferma. \\
& &
\end{tabular}

En una primera lectura, se puede observar una eliminación en Peri Rossi, zangou-se no aparece en su traducción y un error, aunque es imposible definir el origen de éste, cuando se lee "gato" por galo, que en Cámara y Russo sí aparece como "gallo". En cuanto a las elecciones lexicales y gramaticales, se nota de nuevo un esfuerzo en Peri Rossi por intentar seguir de cerca el texto original, tan solo en el primer párrafo, hay una correspondencia de conjugación verbal entre saberia y "sabría", mientras que los argentinos lo traducen como "sabía”. Después, la uruguaya usa la construcción marcada "no había siquiera dónde buscarle una respuesta" para reflejar la sintaxis de Lispector. En ese mismo fragmento, Cámara y Russo vuelven a traducir "no sabía qué responder"; esto explicaría por qué tradujeron saberia por "sabía” ya que existe una repetición que no está en Lispector, posiblemente como una compensación: en el texto original hay más de una repetición, que no siempre se respeta en las traducciones; retomaré este punto más adelante. No obstante, la diferencia gramatical entre usar un copretérito y un pospretérito afecta la manera en que se lee el verbo estativo, en el caso del portugués y la traducción de Peri Rossi no hay una certeza sobre lo que la voz narrativa dice de la mujer, mientras que en Cámara y Russo la voz narrativa afirma, es contundente, con el uso del copretérito de "saber".

En el diálogo de la protagonista, hay una reestructuración sintáctica en ambos casos, se elimina la marca oral ai y sólo Peri Rossi intenta rescatarla con "cuidado con". Las traducciones por lo tanto no reflejarían ese rasgo de oralidad que está en boca del personaje. La decisión de Cámara y Russo queda muy simple, un 
"no molestes" que puede leerse tan impersonal como un aviso de "no molestar" en la puerta de algún hotel.

Respecto a las elecciones léxicas, para rapariga y declarou, la uruguaya usa "muchacha" y "aclaró", los argentinos eligen "muchachita" y "dijo". Si bien considero que declarou tiene sentido de "declaró" o "sentenció" por lo que dice el personaje después, Peri Rossi se aleja del convencional "dijo”. En cambio, Cámara y Russo, al utilizar ese verbo, borran la especificidad del portugués y "muchachita" añade un tono condescendiente; el cambio es extraño además porque en las otras veces que aparece rapariga, incluso en el título, los traductores no optan por el diminutivo. Así, los argentinos modifican el registro del personaje y motivan un efecto de transformación.

\section{Unidad 3}

\begin{tabular}{|c|c|c|}
\hline Lispector (20) & Peri Rossi (12) & Cámara y Russo (10) \\
\hline $\begin{array}{l}\text { Acordou com o dia atrasado, } \\
\text { as batatas por descascar, os } \\
\text { miúdos que voltariam à tarde } \\
\text { das titias, ai que até me faltei } \\
\text { ao respeito!, dia de lavar } \\
\text { roupa e serzir as peúgas, } \\
\text { ai que vagabunda que me } \\
\text { saíste!, censurou-se curiosa } \\
\text { e satisfeita, ir às compras, } \\
\text { não esquecer o peixe, o dia } \\
\text { atrasado... }\end{array}$ & $\begin{array}{l}\text { Despertó con el día atrasado, } \\
\text { las patatas por pelar, los } \\
\text { niños que regresarían por la } \\
\text { tarde de casa de las tías, jay, } \\
\text { me he faltado al respeto!, } \\
\text { día de lavar ropa y zurcir } \\
\text { calcetines, jay, qué haragana } \\
\text { me saliste!, censuróse } \\
\text { curiosa y satisfecha, ir de } \\
\text { compras, no olvidar el } \\
\text { pescado, el día atrasado... }\end{array}$ & $\begin{array}{l}\text { Se despertó retrasada con } \\
\text { las papas por pelar, los niños } \\
\text { que volverían a la tarde de } \\
\text { lo de sus tías, jay, qué falta } \\
\text { de respeto!, día de lavar ropa } \\
\text { y zurcir las medias, jay, qué } \\
\text { haragana me saliste!, se } \\
\text { censuró curiosa y satisfecha, } \\
\text { hacer las compras, no olvidar } \\
\text { el pescado, el retraso... }\end{array}$ \\
\hline
\end{tabular}

En la oración que abre esta unidad de análisis ya se encuentra un cambio importante en la traducción argentina. Lispector enuncia que la muchacha se ha despertado com o dia atrasado: Peri Rossi respeta la frase nominal, pero Cámara y Russo trasladan lo atrasado del día a la muchacha, así queda una oración ambigua con el adjetivo "retrasada" atribuido al personaje, lo que provoca un aumento a esa voz narrativa. Eso no es todo: en la unidad anterior mencioné las repeticiones por pares que hay en el cuento en portu- 
gués, en este fragmento o dia atrasado aparece al principio y hacia el final. El cambio de los argentinos rompe con esa repetición en el español, que en Peri Rossi se mantiene.

El ai que portugués también aparece dos veces y en ambas traducciones permanece sólo con "ay". En ai que até me faltei ao respeito!, aunque Peri Rossi elimina que, mantiene la enunciación con el verbo conjugado en primera persona, por lo que se atribuye enseguida a una marca de la voz del personaje; en cambio, Cámara y Russo sustituyen el verbo por un sustantivo, "falta", e incurren así en una deformación pues la focalización en el personaje no se explicita y la expresión puede atribuirse sólo a la voz narrativa. Se pierde aquí el juego entre voces.

Sobre las elecciones léxicas, hay dos palabras en el original que son características de la variante europea del portugués: miúdos y peúgas. En ambas traducciones miúdos pasa como "niños" y en el caso de péugas, los argentinos se deciden por "medias", palabra propia de su variante del español, esta decisión al traducir es consistente en su trabajo. Más adelante ampliaré mi comentario al respecto, que también incluye otros ejemplos de cambios en los registros, como en el caso de titias en esta unidad, que es una forma familiar, cariñosa, para referirse a las tías, algo así como 'tiíta' y que tanto Peri Rossi como Cámara y Russo traducen llanamente como "tías".

\section{Unidad 4}

\begin{tabular}{|l|l|l|}
\hline Lispector (21-22) & Peri Rossi (13) & Cámara y Russo (11) \\
\hline Naturalmente que ela & Naturalmente que ella & Naturalmente que ella \\
palestrava. Pois que Ihe não & conversaba. Porque no le & charlataneaba. Pues no le \\
faltavam os assuntos nem as & faltaban temas ni habilidad. & faltaban temas ni capacidad. \\
capacidades. Mas as palavras & Pero las palabras que una & Pero las palabras que una \\
que uma pessoa pronunciava & persona pronunciaba cuando & persona pronunciaba cuando \\
quando estava embriagada & estaba embriagada eran & estaba ebria era como si \\
era como se estivesse prenhe & como si estuvieran preñadas: & estuviesen preñadas -palabras \\
- palavras apenas na boca, & palabras sólo en la boca, que & apenas en la boca, que tenían \\
que pouco tinham a ver & poco tenían que ver con el & poco que ver con el centro \\
como o centro secreto que & centro secreto que era como & secreto que era casi como una \\
era como uma gravidez. & una gravidez. & gravidez. \\
\hline
\end{tabular}


En esta unidad, en la que la protagonista ya está en un estado de embriaguez, hay una metáfora insólita que tiene que ver con el cuerpo sexuado; pero en las dos traducciones hay dos cuestiones que modifican el sentido. Cuando Lispector escribió como se estivesse prenhe, por la conjugación verbal y el adjetivo en singular se sabe que se está hablando de uma pessoa; pero en las traducciones esa adjetivación se traslada a "las palabras". Lo segundo es que mientras que en portugués gravidez es el sustantivo usual, que refiere a la etapa en que una mujer está gestando, "gravidez" en español está en un registro formal, incluso casi restringido al ámbito legislativo, por lo que en el efecto interpretativo habrá una transformación, en este caso un sentido de extrañeza ausente en el original, "gravidez" hubiera quedado más justificado si Lispector hubiera utilizado prenhez o ciese, la solución más cercana era "embarazo". Elegí este fragmento porque da cuenta de cómo la traducción de figuras retóricas se complejiza y por la naturaleza de la metáfora, de la cual comentan Mol y Ribeiro "[a]inda com relação à transgressão expressa pela portuguesa, destacamos a comparação, feita pela autora, entre o estado da mulher embriagada ao da mulher grávida" (Mol; Ribero 188); la transgresión de la que hablan tiene que ver con la negación de la protagonista ante sus actividades cotidianas, responsabilidades impuestas por el rol social que está en relación con la comparación entre el embarazo y la embriaguez. Sobre una cuestión léxica, y a manera de introducción para los siguientes comentarios generales antes de concluir, se ve cómo palestrava pasa en la traducción de Cámara y Russo como "charlataneaba", un verbo propio de su variante del español.

Tras el estudio de las cuatro unidades presentadas, puede descubrirse una tendencia en los trabajos de los traductores. Considero que es notorio cómo Cámara y Russo deciden utilizar en su traducción marcas de su variante del español: "apantallar" (7), "charlataneaba" (11), "tilinguita" (13), “medias" (20) son ejemplos de elecciones léxicas que se dirigen a un público argentino. Esto puede explicarse en el origen de la traducción -o el proyecto del traductor, en términos de Berman ( $c f$. 59-62)- pues El cuenco 
de plata, la editorial, pertenecía a Russo y está enfocada en una distribución local; podría decirse que Cámara y Russo sabían que su trabajo era para los lectores argentinos y con esa idea tradujeron con ese público en mente, cuestión en consonancia con la importancia que le daba Russo a su labor como editor. Por otro lado, la traducción de Peri Rossi tuvo una circulación más amplia, por estar hecha en España, el centro de producción y distribución mundial más extenso de traducciones al español.

Por supuesto, la decisión de Cámara y Russo afecta en buena medida la manera en que se lee a Lispector pues tiende además a normalizar rasgos estilísticos, los traductores incurren en deformaciones, aumentos o transformaciones que borran la extrañeza, característica particular de la escritura de Lispector que Helgesson considera que debería ser fácil de traducir: "Al pertenecer a la cultura literaria antes que a la 'étnica', los momentos autorreflexivos de extrañamiento lingüístico en Lispector son sumamente idóneos para la traducción” (Helgesson 328), ${ }^{4}$ por esta razón el estilo de la brasileña sería proclive a la hospitalidad lingüística, término, basado en Ricœur, con el que Helgesson señala un modo de generosidad que el traductor debe aprovechar (ibid.). No obstante, los argentinos no sacaron ventaja de esta hospitalidad.

Peri Rossi, en cambio, intenta ser fiel al original, incluso en expresiones idiomáticas como de mão à ilharga (18), que significa "con soberbia, de modos arrogantes" 5 ("mão"), que se queda como "con la mano en la ingle" (10) en la traducción de la uruguaya, lo que provoca un efecto de contracción pues en español sólo permanece un sentido literal y no el significado de altivez. La expresión (lhe fizera) subir a mostarda ao nariz (23), en portugués "enfurecerse" ("mostarda"), Peri Rossi la traduce como "(le hiciera) subir la mostaza a la nariz” (15), un efecto de transformación pues

\footnotetext{
4 "By pertaining to literary rather than 'ethnic' culture, the self-reflexive moments of linguistic estrangement in Lispector are highly amenable to translation”.

${ }^{5}$ Las traducciones de las definiciones del diccionario son mías. Sigo utilizando las páginas entre paréntesis de acuerdo con la edición del original y las traducciones, según sea el caso.
}

Cad. Trad., Florianópolis, v. 40, n⿳ 1, p. 168-187, jan-abr, 2020. 
el significado se vuelve oscuro. Un ejemplo más, entornar mais $o$ caldo (26), "complicar mucho una cosa" ("caldo") en portugués, pasa como "consiguió un mayor trastorno" (18), aquí la uruguaya no recurrió a la literalidad, pero de igual forma no lo tradujo a una expresión común. Las tres expresiones aparecen respectivamente en la traducción de Cámara y Russo como "los brazos en jarra, con insolencia” (8), “(le había) revuelto la bilis” (13), y “complicó más las cosas" (15), una prueba más de la estrategia de los argentinos.

En ambas traducciones, no obstante, hay inconsistencias, como el uso de diminutivos y aumentativos. De diez derivados que pude identificar (vestidito, santarrona, deditos, etc.), los tres traductores omiten tres:

\begin{tabular}{|l|l|l|}
\hline Lispector & Peri Rossi & Cámara y Russo \\
\hline frescurazita (17) & frescor (9) & fresco (7) \\
\hline adormecidona (20) & adormecida (12) & dormida (10) \\
\hline friozito (25) & frío (16) & frío (14) \\
\hline
\end{tabular}

La presencia de estas palabras es importante en el cuento. Las traducciones potencian efectos de contracción y transformación puesto que modifican la lectura de ciertos registros y, por ende, se pierden marcas estilísticas que evidencian en el original la mezcla de voces narrativas.

\section{Conclusiones}

Con este trabajo pretendí mostrar los distintos caminos a los que puede llevar una traducción y la relevancia que tienen las decisiones de los traductores en sus efectos de interpretación. En una valoración que intenta escapar de emitir un juicio positivo o negativo, se observa que la estrategia de Peri Rossi es extranjerizante, más cercana al texto fuente, mientras que la de Cámara y Russo corresponde con la domesticación de un 
texto, con sus reestructuraciones sintácticas y sus variedades diatópicas. Esta dicotomía se ha descrito de varias formas; uso los términos de Venuti (210-213) porque me parece que explican acertadamente las traducciones, sobre todo la de Cámara y Russo en el que se evidencia esa tendencia por la fluidez, por adaptar el texto a un lector local.

A veces sucede que hay un elemento que entra en la categoría de lo intraducible, la estrategia de Lispector de escribir con rasgos de portugués europeo resulta imposible de reflejar en español. La pérdida que representa se relaciona con el estilo del cuento, la extrañeza en la lectura y la configuración del personaje, incluso llamarla "rapariga" produce una lectura ambivalente en Brasil, pues la palabra es poco usada en el país americano en su acepción de mujer joven, sin embargo, es consignada en algunas regiones brasileñas como "meretriz" ("rapariga") o "mujer que vive con un hombre sin estar casada". Los traductores franceses Jacques y Teresa Thiériot rescatan la caracterización en el título, "Dévanouement et ivresse d'une jeune portugaise", pero no es posible tampoco en esa lengua reflejar el trabajo con la variante europea del portugués en el texto original.

Finalmente, con este análisis quise exponer cuán útil puede ser la crítica de traducciones para los estudios literarios; pues obliga a una lectura más atenta de un texto en su lengua original y sus traducciones que revela rasgos y estrategias narrativas en diferentes lenguas. Comparto la convicción de Haroldo de Campos sobre "la imposibilidad de la enseñanza de la literatura [...] sin que se atienda el problema del manejo de ejemplos y de la crítica vía traducción" (Campos 201) y la considero extensiva a la crítica de traducciones. Por supuesto, quedan en el tintero otras cuestiones, relacionadas con la multiplicidad de perspectivas sobre un texto literario, pero espero haber mostrado que propuestas como la de Hewson, desde los Estudios de Traducción, son productivas y ofrecen otra perspectiva de acercamiento a una obra literaria. 


\section{Referencias}

Berman, Antoine. Toward a Translation Criticism: John Donne. Tradução de Françoise Massardier-Kenney. Ohio: The Kent University Press, 2009.

Bosi, Alfredo. História concisa da literatura brasileira. São Paulo: Cultrix, 2003.

CALDO. Dicionário Priberam da Língua Portuguesa online. Disponível em: https://dicionario.priberam.org/Caldo. Acesso em: 29/05/2019

Campos, Haroldo de. "La traducción como creación y como crítica". In: Campos, Haroldo de. De la razón antropofágica y otros ensayos. Tradução de Rodolfo Mata. Tres Cantos: Siglo XXI, 2000, p. 185-204.

Corrêa dos Santos, Roberto. “Apresentação. Artes de Fiandeira”. In: Lispector, Clarice. Laços de família: contos. Rio de Janeiro: Francisco Alves, 1993, p. 5-14.

Cossío Woodward, Miguel. "Prólogo. De Clarice”. In: Lispector, Clarice. Cuentos reunidos. Comp. Miguel Cossío Woodward, Tradução de varios. Madri: Alfaguara, 2001, p. 15-32.

Erlan, Diego. "Murió Edgardo Russo, una elegante figura de la edición independiente de nuestro país". Clarín, [s.1], 2 jul 2015. Disponível em: www. clarin.com/cultura/edgardo_russo-editoriales_independientes-manuel_puig-copiliteral_0_HJ7tT8tP7g.html. Acesso em:15/05/2019.

Ferreira de Freitas, Luana. "Clarice Lispector's radicality translated into the English-speaking literary system”. Cadernos de Tradução, Florianópolis, vol. 38, núm. 3, 2018, p. 244-258. Disponível em: http://www.scielo.br/scielo. php? script $=$ sci_arttext\&pid $=\mathrm{S} 2175-79682018000300244 \& \operatorname{lng}=$ en $\& \mathrm{nrm}=$ iso. Acesso em: 15/05/2019.

Helgesson, Stefan. "Clarice Lispector, J.M. Coetzee and the seriality of translation”. Translation Studies, [s.1], vol. 3, núm. 3, 2010, p. 318-331. 
Hewson, Lance. An Approach to Translation Criticism: Emma and Madame Bovary in translation. Amsterdam: John Benjamins, 2011.

Lispector, Clarice. Laços de família: contos. Rio de Janeiro: Francisco Alves, 1993 [1960](a).

Lispector, Clarice. Lazos de familia. Tradução de Cristina Peri Rossi. Barcelona: Montesinos, 1988(b).

Lispector, Clarice. Lazos de familia. Tradução de Mario Cámara y Edgardo Russo. Argentina: El Cuenco de Plata, 2010(c).

Lispector, Clarice. Liens de famille. Tradução de Jacques y Teresa Thiériot. Paris: Des Femmes Antoinette Fouque, 1989(d).

Losada, Basilio. "Introducción". In: Lispector, Clarice. Cerca del corazón salvaje. Tradução de Basilio Losada. 2a ed., Madri: Siruela, 2018, p. 9-13.

MÃO. Dicionário Priberam da Língua Portuguesa online. Disponível em: https:// dicionario.priberam.org/m\%C3\%A3o. Acesso em: 29/05/2019.

MOSTARDA. Dicionário Priberam da Língua Portuguesa online. Disponível em: https://dicionario.priberam.org/Mostarda. Acesso em: 29/05/2019.

Mol, Isabela Baião; Ribeiro, Rafael Pacheco Lanes. "Clarice Lispector: 'Devaneio e embriaguez duma rapariga"”. Miguillim - Revista Eletronica do Netlli, [s.1], vol. 3, núm. 3, 2014, p. 181-190. Disponível em: periodicos.urca.br/ojs/index. php/MigREN/article/viewFile/766/745. Acesso em: 15/05/2019

Peri Rossi, Cristina. "Traducir, amar". Artículos de Cristina Peri Rossi, [s.1], 26 nov 2010. Disponível em: perirossiarticulos.blogspot.com/2010/11/traduciramar.html. Acesso em: 15/05/2019.

Pozenato, José Clemente. "Clarice Lispector: la mirada de la mujer". Tradução de Milton Hernán Bentancor. Antares. Letras e Humanidades, [s.1], núm. 3, enejun 2010 p. 160-177. 
RAPARIGA. Dicionário Priberam da Língua Portuguesa online. Disponível em: https://dicionario.priberam.org/Rapariga. Acesso em: 29/05/2019.

RAPARIGA. Dicio - Dicionário Online de Português. Disponível em: https:// www.dicio.com.br/rapariga/. Acesso em: 29/05/2019.

Saldías Palomino, María Amanda. "Cristina Peri Rossi lee a Clarice Lispector: Discurso introspectivo y los límites naturalizados de la "escritura femenina". Acta Literaria, núm. 46, 2013, p. 69-84.

Selicki Acevedo, Carolina. "Lispector y las lenguas”. Página 12, [s.1], 5 ago 2011. Disponível em: www.pagina12.com.ar/diario/suplementos/las12/13-6673-201108-07.html. Acesso em: 15/05/2019.

Terra, Ernani. "Enunciação e o português europeu em um conto de Clarice Lispector", VI Simpósio Mundial de Estudos da Língua Portuguesa, 2017. Disponível em: www.academia.edu/35607679/A_enunciação_em_ Devaneio_e_embriaguez_de_uma_rapariga_de_Clarice_Lispector. Acesso em: $15 / 05 / 2019$.

Venuti, Lawrence, "Translation as Cultural Politics: Regimes of Domestication in English”. Textual Practice, [s.1], vol. 7, núm. 2, 1993, p. 208-223.

Recebido em: 25/08/2019 Aceito em: 31/10/2019 Publicado em janeiro de 2020

Andrés Ramos García. E-mail: andres.ramos@colmex.mx. ORCID: https://orcid.org/0000-0002-5827-3234 